Published as: Van Malderen, L., B. Jourquin, I. Thomas, T. Vanoutrive, A. VerHETSEL \& F. WITLOX (2012) "On the mobility policies of companies: what are the good practices? The Belgian Case". Transport Policy. Vol. 21, pp. 1019.

\title{
ON THE MOBILITY POLICIES OF COMPANIES: WHAT ARE THE GOOD PRACTICES? \\ The Belgian Case
}

\author{
Laurent Van Malderen* \\ Louvain School of Management, FUCaM ${ }^{1}$, Mons \\ Centre for Operations Research and Econometrics, $U C L^{2}$, Louvain-la-Neuve \\ Bart Jourquin \\ Louvain School of Management, FUCaM ${ }^{1}$, Mons \\ Isabelle Thomas \\ Centre for Operations Research and Econometrics, and Department of Geography, \\ $U C L^{2}$, Louvain-la-Neuve \\ Thomas Vanoutrive \\ Department of Transport and Regional Economics, $U A^{3}$, Antwerp \\ Ann Verhetsel \\ Department of Transport and Regional Economics, $U A^{3}$, Antwerp \\ Frank Witlox \\ Social and Economic Geography Research Group, $U G^{4}$, Ghent
}

\author{
*Corresponding author: \\ vanmalderenl@fucam.ac.be \\ +32(0)65323424 \\ Chaussée de Binche, 151 \\ 7000 Mons
}

\footnotetext{
${ }^{1}$ Catholic University Faculties of Mons

${ }^{2}$ Catholic University of Louvain

${ }^{3}$ University of Antwerp
} 


\begin{abstract}
As the sources of commuting traffic, companies have an important role in the mobility debate. In recent years, they have developed a variety of initiatives to improve the mobility of their employees. Though, their visions and actions are often neglected in the research literature. This paper aims at identifying the "good practices" of mobility policies of workplaces located in Belgium. To achieve this objective, existing researches and two large-scale Belgian surveys of commuting are analysed. First, a classification method is applied to the data in order to identify the workplaces where the alternative modes of transport which are promoted by the policy are popular among employees. Then, quantitative analyses are performed to find out what the good practices of mobility policies are.

The results show that the best way of promoting an alternative mode of transport depends on the company's characteristics. The promotion of bicycles suits small workplaces best, while larger workplaces and those located in built-up areas or city centres suit the promotion of public transport best. Financial incentives, provision of facilities, diffusion of information, and parking management play all an important role in mobility management.
\end{abstract}

KEYWORDS: commuting, employer transport plan, sustainable commuting

\title{
1. Introduction
}

Companies are important actors in the mobility debate. As sources of home-to-work journeys they generate repeated and concentrated traffic. Still based on the car, the volume of this traffic is often too large for the road capacity and clogs up main cities. The consequent congestion threatens the economic competitiveness of countries (Vickerman, 2003). In fact, it is difficult to conceive of strong and durable economic growth without an effective transport system. In addition, the necessity of reducing air pollution makes the rationalisation of car use essential. Aware of this problem, many companies have developed initiatives, called "mobility policies", to reduce or control the number of Single-Occupant Vehicles (SOVs) linked to their workers.

Nevertheless, the visions and actions of companies are largely neglected in the literature. Existing researches on commuter traffic often start with a behavioural analysis of the individual commuter (e.g. Hensher and Rose, 2007) or from an analysis at the municipality level (e.g. Rietveld and Daniel, 2004). Hence, the main objective of this paper is to work out what the "good practices" for mobility policies are by analysing 2 large-scale Belgian surveys of commuting

The involvement of companies in a sustainable mobility management is not a recent phenomenon. A decisive step was the introduction in 1988, in South California (in the Clean Air Act, Regulation XV), of a new concept, Transport Demand Management (TDM), which encompasses both alternatives to drive alone and strategies promoting other ways of getting to work. Many applications have been found at the company level because of the possibilities of partnership between employers, and the predictable and repeated pattern of commuting. In addition to address the growing environmental issue, 
mobility also represents an opportunity for employers to achieve business objectives (Roby, 2010). In fact, a successful mobility policy can save, or at least greatly reduce, the costs linked to the commuting of employees by car (e.g. the rental of parking spaces). Hence, the concept of an Employer-based Mobility Programme (EMP) appeared and was spread within companies. More and more public and private employers have then developed and implemented such programmes.

The practical forms taken by mobility policies are directly affected by the characteristics of the organisation implementing it, and by management's specific objectives. The elements making up an EMP have thus to be adjusted depending on a number of factors such as the location of the workplace, the type of workforce (Comsis Corporation, 1993; Hendricks and Joshi, 2004) or the objectives aimed by the managers. Mobility policies (i.e. EMPs) are thus polymorphous and specific to each company. This makes the identification of "good practices" more complex.

The paper starts with an overview of the literature on the mobility management by the employers (Section 2). The following section is devoted to the analysis of the mobility policies of the workplaces of the companies located in Belgium. This analysis is made on the basis of classifications of the workplaces. The aim is to identify the workplaces where the alternative modes of transport which are promoted are popular among the employees. In fact, one can assume that 'good practices' of mobility policies are more likely to be found in those companies. In Section 4 some good practices are identified through quantitative analyses of both this classification and the development through time of employees' commuting behaviour. The final section (Section 5) discusses the results in order to outline the conclusions in the form of some policy recommendations.

\section{Mobility management by employers}

In order to promote a more sustainable mobility, companies have developed initiatives that can be grouped into two categories: alternative travel options, and pull and push measures. This section offers an overview of these categories and of their associated initiatives. For a more exhaustive literature review see Vanoutrive et al. (2010).

\subsection{Alternative modes of transport}

In recent years, with the growing awareness of environmental issues, a lot of measures promoting alternative modes of transport have been developed. An EMP can encourage employees to choose environmentally-friendly ways of commuting (Kingham et al., 2001; Dickinson et al., 2003). However, these travel-related strategies are affected by the subjective assessments, desires and affinities of individuals, as well as their attitudes to travel, personalities and lifestyles. Consequently putting such a plan in place requires an understanding of the role of numerous variables, which complicates the design of policies (Cao and Mokhtarian, 2005). Two main groups of alternative travel options exist: nonsingle modes of transport, and non-motorised modes of transport.

1) Non-single modes of transport 
Non-single alternatives to SOV use include public transport and ridesharing. Ridesharing consists in sharing a vehicle (e.g. a car or a van) for a travel. Regardless of the number of occupants, the common element of non-single modes of transport is that each additional user represents another motorised trip removed from the road network. Car-sharing is the most common form of ridesharing promoted by companies. In such an arrangement, two or more employees drive to work together in a personal or company-owned car (Vanoutrive et al., 2010). The main advantages of this option, compared to public transport, are its door-to-door directness and its convenience which are similar to that of a SOV use (Comsis Corporation, 1993).

Strategies to promote public transport are difficult to put in place within a company. The car certainly has an instrumental function, but it also has important symbolic and affective functions (Steg, 2005). The location of the workplace is particularly important when considering public transport: a large site, good access to public transport, restricted parking, and long commutes are conditions that encourage the use of public transport (Hwang and Giuliano, 1990; De Witte et al., 2008). However, people still view public transport as a troublesome option. This could be improved if some of the inconveniences (such as infrequency, unreliability, inconvenient drop off sites, poor connections and expensive tickets) were removed (Kingham et al., 2001; De Witte et al., 2008).

\section{2) Non-motorised modes of transport}

Non-motorised alternatives to the car include cycling and walking. They do not use much road capacity and are environmentally friendly. These "green" commuting modes are particularly well adapted to urban or short trips where they can result in considerable time savings. EMPs often consider only cycling when promoting non-motorised modes of transport. In fact, the cyclist can cover longer distances than the walker. Journeys of less than 5 kilometres are within cycling distance for most people, and cycling potential exists up to about 10 kilometres (Rietveld, 2001; Vandenbulcke et al., 2009). The promotion of cycling mainly focuses on improving safety and work-based amenities such as bicycle parks and changing facilities. As well as distance, the success of such measures depends on many other variables, making it difficult to apply them universally. Important variables include physical factors such as topography (hills) and meteorological conditions (rainfall and wind speed), and individual ones such as gender, age, education, income, and the urban parameters (Ortúzar et al., 2000; Rietveld, 2001; Dickinson et al., 2003; Vandenbulcke et al., 2009; Vanoutrive et al., 2010).

\subsection{Pull and push measures}

Costs, both in monetary terms and in travel time, and convenience are commonly accepted as being the two key factors in a commuter's choice of a mode of transport (Comsis Corporation, 1993; Hagman, 2003; Anable, 2005). Although most alternatives to the car offer a cost advantage through the sharing or eliminating of expenses, many commuters weigh this saving against the potential reduction in convenience and choose to drive alone (Rodriguez and Joo, 2004). Pull and push measures act on both factors, and are essential components of every EMP where they need to be combined in mutually supportive packages (Koppelman et al., 1993; Banister, 2008). 


\section{1) Pull measures}

Pull measures are measures which reward workers who reduce their car use. Popular and simple to introduce, they often consist of financial incentives to employees who choose an alternative mode of transport to commute. Commuters respond to strategies that offer a tangible value (Hwang and Giuliano, 1990). Pull measures compensate for the disadvantages of other modes of transport, and can provide a strong economic incentive to shift from SOVs. However, this kind of measure often represents a cost for the employers (e.g. due to the need to pay for allowances). The suitability of such measures within companies is intimately linked to their aims. Pull measures have to be appropriate, given the promoted alternative modes of transport and the particularities of the workplace, as described above.

\section{2) Push measures}

Push measures try to discourage solo driving. The main push measures are related to parking management. Indeed a change to sustainable ways of commuting also has implications for site issues, and especially for parking: only a few people will give up their cars unless measures to make parking on-site less attractive (e.g. parking charges) are introduced (Hole, 2004; Van Exel and Rietveld, 2009). Another lever for push measures is the management of company cars. The provision of company cars is often associated with high levels of employees driving to work alone.

\section{Classifying and analysing mobility policies}

The aim of this paper is to work out what the "good practices" of EMP are. To achieve this objective, data of a large-scale Belgian survey is used and two analyses are performed: first a cross-sectional one based on workplaces' classifications; and secondly an analysis of the development over time of workplaces' mobility policies and of the modal splits. This section present the data set and the methodology used in this paper.

\subsection{Data set}

Articles 160 to 170 of the Belgian programme-law of April $8^{\text {th }} 2003$ established a legal obligation for all private and public companies located in Belgium and employing at least a hundred workers to fill in the three-yearly HTWT questionnaire for every of their workplaces employing at least 30 workers. The survey is conducted by the "Federal Public Service (FPS) Mobility and Transport". It mainly focuses on the mobility measures taken by companies and on the commuting behaviour of their workers. The first two surveys (2005 and 2008) are available and 3,269 and 3,733 companies respectively filled in the forms. The databases contain information about 7,460 and 9,455 workplaces in 2005 and 2008 respectively. This represents the commuting behaviour of about one worker out in three in Belgium.

Mobility policies have been divided into four groups of measures: those promoting the use of bicycles (15 measures), of carpooling (6), of public transport (6), and miscellaneous measures (11). Data on 38 possible measures is available (Appendix A). However note that the miscellaneous measures are marginal in the sample, and/or not 
related to a specific mode of transport. Hence only the first three categories, which are pull measures promoting SOV alternatives, are used in this paper. The employers also have to give some information about the mobility problems faced by their employees (Appendix B). The mobility problems are related to the use of: cars and motorbikes (5 potential problems), bicycles (6), public transport (7), and miscellaneous (11). Similarly to the mobility measures, the miscellaneous category is not related to a particular mode of transport and is omitted from the analysis.

The databases also contain information about the main mode of transport used by the employees to commute. There are nine possible choices: car, carpooling, bicycle, motorbike, walking, train, regional public transport (bus, tram and metro), public transport organised by the employer, and "other". "Other" seems to have been chosen when different arrangements are made for going to work and returning home, or when the mode of transport varied according to the weather. Thus, the databases contain the percentage workers at each workplace who used each mode of transport. The percentage of car users and of motorbike users were grouped together, as well as the percentage of train users and of regional public transport users. The aim is to improve the match between the pull measure categories of the mobility policies and the mobility problems in the database. The new categories defined are: private motorised modes of transport, public transport, bicycle, and carpooling. The use of public transport organised by the employer, walking and "other" are aggregated into a "miscellaneous" category, which groups minority modes of transport.

Finally the database was enriched with data on the travel-to-work areas in Belgium (De Wasseige et al., 2000), and the functional urban region (city centre, built-up area, suburb, industrial area and other; Luyten and Van Hecke, 2007) of the workplaces. The information about travel-to-work areas is used to cluster companies by the travel behaviour of their employees, while the functional urban regions is used as explanatory variables in the binary choice model (see 3.2. below).

\subsection{Methodology}

As stated above, the methodology of the paper is split into two phases: in one hand, a cross-sectional analysis of the mobility policies and, in the other hand, an analysis of the development over time of the mobility policies and of the commuting behaviour of the employees. This methodology with two steps brings a better insight into the effects of mobility policies and allows the robustness of the results to be tested.

\subsubsection{Cross-sectional analysis}

The cross-sectional analysis of the mobility policies (Figure 1) is based on: first a classification of workplaces in order to define a binary dependent variable which identifies the workplaces where the alternative modes of transport promoted by the policy are popular among the employees; and secondly an analysis of the results of this classification through a binary choice model in order to identify what the mobility "good practices" are. 


\section{Figure 1: Summary of the cross-sectional analysis methodology}

The choice to use such a methodology is motivated by the fact that it only requires crosssectional data. These types of data are often the only available. In addition, the use of a binary choice model allows performing an analysis at the company level. In fact, data on some control variables (e.g. origin of the home-to-work travels, individual characteristics of the commuters, etc.) are missing. This makes difficult the explanation of the modal choices of workers. These variables are not necessary in the cross-sectional methodology of this paper. Indeed, the binary choice model only explains differences in classification of workplaces. Thus, the analysis identifies the factors which are discriminatory. As mobility policies' "good practices" contribute to the popularity of alternative modes of transport among the employees, one can assume that these "good practices" are more likely to be found in the workplaces where the alternative modes of transport promoted are popular.

\section{i. Classifications of workplaces}

Two cluster analyses based on the Ward's hierarchical clustering method (Ward, 1963) were performed on the workplaces of the 2005 HTWT survey: the first classified workplaces on the basis of their mobility policies, and the second on the basis of the commuting behaviour of their employees. The choice of a hierarchical clustering method was motivated by the fact that it allows the calculation of clustering statistics (Cubic Clustering Criterion, pseudo $\mathrm{T}^{2}$ and pseudo F). These statistics were used in order to define the number of clusters to be identified. The Ward's method was preferred due to Kuiper and Fisher (1976) and Blashfield (1976) evidences that it outperforms other hierarchical methods for clustering. Finally, it uses a linkage function computed as the error sum of squares (ESS), allowing both the minimisation of the variance within clusters and its maximisation between clusters. As a result the clusters it identifies are homogeneous.

Note that there is a slight difference between the methodologies used for the 2 classifications. In the first, the binary nature of the variables (i.e. the presence or not of a mobility measure) compelled us to start with a correspondence analysis in order to convert the dichotomous values into continuous ones. This also allowed the relationship between the variables to be analysed. In the second clustering, the difficulty resided in the disparity of workers' behaviour across Belgium. The topography linked to various variables (urbanisation, infrastructures, etc.) makes a direct comparison between areas hazardous. The use of bicycles is much more widespread in the northern part of Belgium than in the south, while public transport is more developed in large urban centres (Vandenbulcke et al., 2009). To get around this problem, the classification was performed by travel-to-work areas. As the majority of the population of a travel-to-work area works and lives in this area (De Wasseige et al., 2000), a comparison of the commuting behaviour of workers in the same area is meaningful, because all their commuting trips are undertaken in roughly the same topographical terrain.

\section{ii. Identifying "good practices"}


The mobility policies are then analysed in order to identify mobility policy "good practices". A binary choice model is used for this purpose. In fact, the comparison of the two clustering (see above) allows the definition of a binary dependant variable. This variable takes the value of 1 for each workplace where the modes of transport promoted by its mobility policy correspond to those which are used by the workers to commute. In that case, one can assume that the popularity of the mode of transport is the results of characteristics of both the workplace and the mobility policy. In other words, one can assume that these workplaces have "good practices". On the contrary, the dependent variable takes the value of 0 for the workplaces where the above criterion is not meet. The dependent variable is thus defined at the workplace level.

Different model structures of discrete choice model are tested. They all lead to the same conclusions in this analysis and consequently only the results of the logit specification are presented here.

\subsubsection{Developments over time}

The availability of identical HTWT surveys at two different times (2005 and 2008) allows the development of companies' mobility policies and their effects on the commuting behaviour of employees to be analysed. Moreover the scope of the surveys, which also cover workers' problems in getting to work, allows the relationship between problems in 2005 and mobility measures taken by employers in 2008 to be compared. Two statistical methods were employed to analyse the developments over time: correspondence analyses and comparisons of means.

\section{Results}

\subsection{Cross-sectional analysis}

\subsubsection{Classifications of the workplaces}

\section{i. Mobility policies}

The workplaces of the 2005 HTWT survey were classified on the basis of their mobility policies. A correspondence analysis had previously been performed in order to convert the dichotomous values of the variables (presence or not of a measure) into continuous ones. The results of the correspondence analysis also allow the relationship between the mobility measures to be examined. Figure 2 shows that there were three broad types of mobility policy: those based on the promotion of bicycle; those centred on public transport (bus, tram, metro and train); and those promoting carpooling. Consequently, and as no consensus can be found among the clustering statistics, the number of clusters to be identified was fixed at four, to allow the possibility for a workplace to have no mobility policy.

Figure 2: Correspondence analysis of the relationship between mobility measures 
The mobility policies of the four clusters obtained by the Ward's classification are based on: no measure (1,689 occurrences), financial incentives for the use of bicycles and/or public transport $(2,427)$, providing cycling facilities $(2,450)$, and information and/or collaboration incentives with a mix of measures to promote carpooling and public transport (804).

Note that the clusters are somewhat complex. The four clusters identified are not completely disjointed. Every cluster does not correspond to the promotion of only one mode of transport (e.g. the cluster of financial incentives for the use of bicycles and/or public transport). Consequently, a second analysis has been performed thereafter in order to assign one (or several) mode(s) of transport to each workplace. To achieve that, conditions on the mobility measures in force were set in addition to the cluster analysis (Table 1). However, as a workplace could promote several mode of transport the number of mobility policies of the Table 1 exceeds the number of workplaces. Table 1 shows this final classification.

Table 1: Classification on the basis of the mode of transport promoted

\begin{tabular}{|c|c|}
\hline $\begin{array}{l}\text { Mode of transport } \\
\text { promoted }\end{array}$ & $\begin{array}{l}\text { Number of mobility } \\
\text { policies promoting this mode of transport }\end{array}$ \\
\hline Bicycle & 3,641 \\
\hline Public transport & 1,792 \\
\hline Carpooling & 768 \\
\hline Total & 6201 \\
\hline
\end{tabular}

\section{ii. Commuting behaviour of the employees}

The second clustering aims to classify the workplaces in the 2005 HTWT diagnosis by the commuting behaviour of their employees. A classification was performed within each travel-to-work area. The clustering statistics show that the optimal number of cluster has to be set to five. This number of clusters was hence used. It is not surprising as it corresponds to the number of possible modes of transport resulting from the gathering of the variables of the database (see Section 3.1). Thus, the results show that each cluster is linked to a group of workplaces where a mode of transport predominates or is well represented. As expected, the cluster associated with private motorised modes of transport covers most of the workplaces $(4,093)$. It is followed by the clusters for public transport $(1,368)$, cycling $(1,345)$, miscellaneous modes of transport $(348)$ and carpooling (274).

Four additional clusters were identified in some travel-to-work areas. These clusters are made up of workplaces where 2 or 3 alternative modes of transport are highly used by the employees to commute. These clusters are associated to the use of both carpooling and public transport (18 workplaces), bicycles and carpooling (3), bicycles and public transport (7) and finally bicycles, carpooling and public transport (4).

\subsubsection{Identifying "good practices"}


The results of the 2 clusterings are compared. As outlined in Section 3.2.1, a binary variable is defined and takes the value of 1 for each workplace where the mode of transport promoted by the policy (i.e. the cluster of mobility policy) corresponds to the one which is used by the workers to commute (i.e. the cluster of commuting behaviour). 1,306 mobility policies meet this criterion (Table 2). Comparisons of means and Wilcoxon tests show that these workplaces have significant higher percentages of workers commuting with the mode of transport promoted. This shows the validity of the methodology based on clusterings to identify the workplaces where the modes of transport promoted are used by the employees.

Table 2: The final classification of mobility policies

\begin{tabular}{|l|r|r|r|r|}
\hline \multirow{2}{*}{$\begin{array}{c}\text { Mode of transport } \\
\text { promoted }\end{array}$} & \multicolumn{4}{|c|}{ Mode of transport used by the workers to commute } \\
\cline { 2 - 5 } & \multicolumn{3}{|c|}{ Correspondence } & No correspondence \\
\cline { 2 - 5 } & $\mathrm{N}$ & $\%$ & $\mathrm{~N}$ & $\%$ \\
\hline Bicycle & 849 & 23.32 & 2,792 & 76.68 \\
\hline Public transport & 418 & 23.33 & 1,374 & 76.67 \\
\hline Carpooling & 39 & 5.08 & 729 & 94.92 \\
\hline Total & $\mathbf{1 3 0 6}$ & $\mathbf{2 1 . 0 6}$ & $\mathbf{4 8 9 5}$ & $\mathbf{7 8 . 9 4}$ \\
\hline
\end{tabular}

As shown in Table 2, nearly one in four mobility policies based on the promotion of the use of bicycles or public transport meet the criterion. On the other hand, this is the case for only five percents of the strategies promoting carpooling. This low percentage suggests that carpooling-based programmes have difficulties to convince workers. This is probably explained by three factors: firstly the uncertainty and variability of the concept, secondly its relative "novelty" in 2005 and, lastly, its lack of convenience. In fact, carpooling depends on being able to find a partner to travel with. This creates some dependence on other people. This is not true for cycling or public transport. Uncertainty (about schedules, returning home, daily nature, etc.) rapidly appears, and the scheme depends on being able to build a strong personal relationship (e.g. friendship) with the partner. It is also worth noting that $20 \%$ of home-to-work trips are indirect in Belgium (Cornelis, 2009). People often have rather complex mobility behaviours (e.g. dropping children at school before going to work). These travel behaviours represent a major obstacle to the development of carpooling.

The mobility policies were then analysed using a binary-choice model. Three kinds of variables were incorporated in the model: pull measures provided by the mobility policies (listed in Appendix A), characteristics of the workplace (number of workers, number of bicycle racks, type of location and proximity to public transport stops) and reported mobility problems (listed in Appendix B). Note that no explanatory variable about the characteristics of the workers was considered. No data concerning the characteristics of the workers was available. The important size of the sample (7,460 observations) did not allow a data-gathering.

Condition indices, tolerances and Variance Inflation Factors (VIF) were firstly computed in order to test the presence of multicolinearity among the variables. This hypothesis was rejected. LM tests for heteroskedasticity (Davidson and MacKinnon, 1993) were then conducted on the results and reject the presence of heteroskedasticity. Non-significant variables were suppressed from the models. The results of the logit specification are 
presented in Appendices $\mathrm{C}$ and D. The results for the carpooling model are not presented here because the model fit statistics are not conclusive. The few percentage of observations meeting the classification criteria probably explains this lack of fit.

The results suggest that the pull measures that increase the probability of workers to use cycling to work are an additional payment for cycling, the availability of bicycles for work trips, provision of bicycle racks and sheltered bicycle racks, and information about cycling routes. For public transport the most effective measures are an additional payment for using public transport, information about timetables, and encouragement to use public transport for work trips. Surprisingly, the provision of showers and repair facilities for bicycles appear to be ineffective measures. The same is true for the coordination with the public transport. Perhaps these measures are taken at inappropriate workplaces, where they tackle the symptoms rather than the underlying problems (poor cycling infrastructure, location, etc.).

A shortage of parking places for cars also increases the probability the workers use the bicycle and public transport to commute. It assumes the potential efficiency of parking management. Reducing the number of car parks appears thus to be an efficient push measure. On the other hand, the perception that cycling routes are dangerous and public transport insecure reduces the use of bicycles. This confirms the efficacy of building cycling infrastructure, and suggests that public transport is seen as an alternative to cycling (e.g. in bad weather). The importance of quick and secure public transport services with convenient schedules for encouraging commuting by public transport is also confirmed by the analysis.

Finally the characteristics of the workplace that favour sustainable mobility patterns can also be identified. Workplaces with a small number of employees are more likely to have workers commuting by bicycle. Employees at large workplaces located in the built-up areas or in the city centres are more likely to travel to work by public transport.

\subsection{Mobility policies and the development of commuting behaviour}

The availability of two identical HTWT surveys conducted at different dates (2005 and 2008) enables to analyse the development of companies' mobility policies and their impact on the commuting behaviour of their employees. There are 5,009 workplaces which participated in both surveys. Four groups of workplaces can be identified: those having maintained or modified their mobility policies (3,518 workplaces); those having introduced a policy (739); those having abandoned their policy (409); or those without any mobility policy at either date (491).

This classification shows that companies' interest in mobility is increasing. Only $17.9 \%$ of the workplaces which participated in both surveys did not have a mobility policy in 2008 (compared to $22.6 \%$ in 2005). The workplaces which had a mobility policy at both dates removed an average of 1.6 measures in the period between both surveys. However, they introduced 2.3 new measures, so increasing their average number of mobility measures. This probably indicates an increase in managers' knowledge of the efficacy of particular measures. Nonetheless a correspondence analysis between the mobility measures introduced between 2005 and 2008, and the mobility problems identified in 
2005 (see Appendices A and B) shows that there is no relationship (Figure 3). The same is true for companies introducing a mobility policy for the first time between 2005 and 2008. This suggests that companies do not try to rectify specific problems encountered by their workers (e.g. a lack of some specific facilities).

\title{
Figure 3: Correspondence analysis between the new mobility measures introduced between 2005 and 2008 and the mobility problems reported in 2005
}

\author{
Source: HTWT surveys, 2005 and 2008
}

Companies' growing interest in mobility is evident in the way their employees travel to work. There are significant differences between the commuting practices of workers in workplaces which have invested in sustainable mobility and those which have not. Wokrplaces which had a mobility policy in both 2005 and 2008 had a significantly lower rate of SOV usage than other workplaces (Appendix I). Moreover the change in behaviour appears to be towards greener modes of transportation, such as the bicycle and carpooling. Interestingly the greatest gains in commuting behaviour are in companies which had an ongoing mobility policy. At the opposite, companies which had stopped their mobility policy have higher mean rates of SOV use, higher even than that in 2005. This suggests that a worsening in the situation (i.e. removing some facilities) discourages workers in their efforts to "go green". Appendices F, G and H show the shifts towards bicycle use, public transport and carpooling respectively.

These results are confirmed by the analysis of the changes in mobility measures between 2005 and 2008, and of their effect on employees' commuting behaviour. Appendix I shows that removing some mobility measures is associated with a significant decrease (rain clothes and bicycle maintenance) or stagnation (showers) in the proportion of commuters who cycle. Moreover the proportions of commuter cyclists were significantly higher in 2008 in workplaces which had continuing policies to make extra payments for cycling either to-and-from work or on work trips, and in workplaces which provided sheltered bicycle racks and bicycles for work trips (Appendix J). The same is true for commuting by public transport in workplaces which consistently paid for, provided information about public transport, encouraged its use for work trips, and coordinated with public transport. The workplaces which have organised carpooling in 2005 and in 2008 have also more carpoolers than the other workplaces. These results are mainly consistent with the cross-sectional analysis discussed above.

\section{Discussion and conclusions}

This paper has investigated on the role of companies in the promotion of sustainable mobility in Belgium. The results are based on quantitative analyses of Belgian large scale surveys. They show that most companies located in Belgium are aware that mobility is an important issue. Managers act accordingly. Thus the number of workplaces implementing an EMP rose between 2005 and 2008 as did the average number of policy measures in each programme. 
However, it appears that mobility is not the main motivation of companies to invest in such programme. In fact, no relationship is found between the mobility measures introduced by the workplaces and the mobility problems they faced. This confirms the findings of Rye (1999), Blauwens et al. (2008) and Roby (2010): transport policy seems to be a tool to fulfil demands outside the field of transport. Conducting further research on the motivations that drive to the implementation of an EMP within a workplace could thus appear to be useful.

It also appears that numerous mobility policies were reengineered during the studied period: some measures were dropped from the mobility policy and some new ones were introduced. This suggests that managers are gaining in experience in the mobility field and that they are monitoring the policies to improve their effectiveness. The effects of this awareness-raising are translated into modal shifts in favour of alternative modes of transport and consequently into a small reduction in the overall proportion of SOV commuting in Belgium.

At the EMP level, the financial incentives and the provision of facilities appear to be "good practices" of mobility policies. This is consistent with the literature on both EMP (Kingham et al.,2001; Dickinson et al., 2003; De Witte et al., 2008; Cairn et al., 2010) and commuting, which shows that costs and convenience are the key criteria of a transport mode choice (Hagman, 2003; Anable, 2005). Also some less costly measures appear to be effective: strategies favouring trials of alternative modes of transport and the diffusion of information. Finally, as outlined by Modarres (1993), Rietveld et al. (2009) and Cairn et al. (2010), parking management either for car parking than bicycle parks is important in an EMP. This kind of measures has a real power on inducing modal shifts in favour of alternative modes of transport.

Nevertheless, the Belgian commuter is still strongly reliant on SOV and it appears that the mode of transport which is promoted is used by the workers in only a minority of workplaces. This suggests that mobility policies probably suffer from a lack of integration in Belgium. In fact, the results show that they are mainly based on the implementation of measures promoting only one specific alternative mode of transport (bicycle, public transport or carpooling). Most decision-makers do not seem to have adopted an integrated vision and do not promote several mode of transport. Moreover many companies adopt policy measures of a similar nature, and consider them individually and not as a part of an integrated mobility policy. This probably reduces their influence in promoting a move away from driving to work alone.

However, cycling, public transport and carpooling are all realistic alternatives to the single-occupancy car use. Companies have a great potential to influence commuters and the modes of transport that they choose. They have powerful levers at their disposal, but if these are to be really effective they have to be combined in integrated mobility policies to promote various alternative modes of transport and to promote them with various mobility measures. 


\section{References}

Anable, J. (2005) "Complacent car addicts" or "aspiring environmentalists"? Identifying travel behaviour segments using attitude theory. Transport Policy 12 (1), 65-78.

Banister, D. (2008) The sustainable mobility paradigm. Transport Policy 15 (2), 73-80.

Bernardino, A.T. (1995) Adoption of telecommuting: modelling the employer's and the employee's decision processes. PhD Thesis, Massachusetts Institute of Technology.

Blashfield, R.K. (1976) Mixture model tests of cluster analysis: accuracy of four agglomerative hierarchical methods. The Psychological Bulletin 83, 377-388.

Blauwens, G., P. De Baere, and E. Van de Voorde (2008) Transport Economics. Antwerp: De Boeck.

Bosch, G. (1990) From 40 to 35 hours: reduction and flexibilisation of the working week in the Federal Republic of Germany. International Labour Review 129, 611-627.

Breaugh, J.A. (1983) The 12-hour work day: differing employee reactions. Personnel Psychology 36, 277-288.

Brinton, R.D. (1983) Effectiveness of the twelve-hour shift. Personnel Journal 62 (5), 393-398.

Cairns, S., C. Newson and A. Davis (2010) Understanding successful workplace travel initiatives in the UK. Transportation Research A 44, 473-494.

Cao, X. and P.L. Mokhtarian (2005) How do individuals adapt their personal travel? Objective and subjective influences on the consideration of travel-related strategies for San Francisco Bay Area commuters. Transport Policy 12 (4), 291-302.

Comsis Corporation (1993) A Guidance Manual for Implementing Effective EmployerBased Travel Demand Management Programs. Washington, the Institute of Transportation Engineers.

Cornelis, E. (2009) Les déplacements domicile-travail, colonne vertébrale de la mobilité? In: CIEM Mobility Day, Brussels, Belgium, 17 ${ }^{\text {th }}$ February 2009 (in French).

Cuvillier, R. (1984) The Reduction of Working Time. Geneva, International Labour Office,.

Davidson, R and J.G. MacKinnon (1993) Estimation and inference in econometrics. New York, Oxford University Press.

De Wasseige, Y., M. Laffut, C. Ruyters and P. Schleiper (2000) Bassins d'emploi et regions fonctionnelles. Méthodologie et définition des bassins d'emploi belges. Service des études et de la statistique, Discussion paper 2005 (in French).

De Witte, A., C. Macharis and O. Mairesse (2008) How persuasive is "free" public transport? A survey among commuters in the Brussels Capital Region. Transport Policy 15 (4), 216-224.

Dickinson, J.E., S. Kingham, S. Copsey and D.J. Pearlman Hougie (2003) Employer travel plans, cycling and gender: will travel plan measures improve the outlook for cycling to work in the UK? Transportation Research D 8 (1), 53-67. 
Fenn, D. (1995) Long hours for long weekends. Inc. 17 (6), 137.

Hagman, O. (2003) Mobilizing meanings of mobility: car users' constructions of the goods and bads of car use. Transportation Research D 8 (1), 1-9.

Helminen, V. and M. Ristimäki (2007) Relationships between commuting distance, frequency and telework in Finland. Journal of Transport Geography 15, 331-342.

Hendicks, S.J. and A. Joshi (2004) Commuter choice program case study development and analysis. Center for Urban Transportation Research (www.nctr.usf.edu/pdf/52706.pdf).

Hensher, D.A. and J.M. Rose (2007) Development of commuter and non-commuter mode choice models for the assessment of new public transport infrastructure projects: a case study. Transportation Research A 41 (5), 428-443.

Hole, A. (2004) Forecasting the demand for an employee park and ride service using commuters' stated choices. Transport Policy 11 (4), 355-362.

Hung, R. (1996) Using compressed workweeks to reduce work commuting. Transportation Research A. 30 (1), 11-19.

Hwang, K. and G. Giuliano (1990) The Determinants of Ridesharing: Literature Review. Working Paper, UCTC No. 38.

Kingham, S., J. Dickinson and S. Copsey (2001) Travelling to work: will people move out of their cars? Transport Policy 8 (2), 151-160.

Koppelman, F., C. Bhat and J. Schofer (1993) Market research evaluation of actions to reduce suburban traffic congestion: commuter travel behaviour and response to demand reduction actions. Transportation Research A 27 (5), 383-393.

Kuiper, F.K. and L. Fisher (1975) A Monte Carlo comparison of six clustering procedures. Biometrics 31, 777-783.

Latona, J.C. (1981) Flexitime and the compressed workweek for the small firm: some employee reactions. American Journal of Small Business 5, 23-29.

Lund, J. and P.L. Mokhtarian (1994) Telecommuting and residential location: theory and implication for commute travel in the monocentric metropolis. Transportation Research Record 1463, 10-14.

Luyten, S. and E. Van Hecke (2007) De Belgische stadsgewesten 2001. Statistics Belgium working paper, $\mathrm{n}^{\circ} 14$ (in Dutch).

Mokhtarian, P. (1991) Defining telecommuting. Transportation Research Record 1305, 273-281.

Nilles, J.M. (1988) Traffic reduction by telecommuting: a status review and selected bibliography. Transportation Research A 22A (4), 301-317.

Nilles, J.M. (1991) Telecommuting and urban sprawl: mitigator or inciter? Transportation 18, 411-432.

Ortúzar, J. de D., A. Iacobelli and C. Valeze (2000) Estimating demand for a cycle-way network. Transportation Research A 34 (5), 353-373. 
Rietveld, P. (2001) Biking and walking: the position of non-motorised transport modes in transport systems. Tinbergen Institute Discussion paper. Paper TI 2001-111/3.

Rietveld, P. and V. Daniel (2004) Determinants of bicycle use: do municipal policies matter? Transportation Research A 38 (7), 531-550

Roby, H. (2010) Workplaces travel plans: past, present and future. Journal of Transport Geography 1 (18), 23-20.

Rodriguez, D.A. and J. Joo (2004) The relationship between non-motorized mode choice and the local physical environment. Transportation Research D 9 (2), 151-173.

Rye, T. (1999) Employer attitudes to employer transport plans: a comparison of UK and Dutch experience. Transport Policy 6 (3), 183-196.

Steg, L. (2005) Car use: lust and must. Instrumental, symbolic and affective motives for car use. Transportation Research A 39 (2-3), 147-162.

Sundo, M.B. and S. Fujii (2005) The effects of compressed working week on commuter's daily activity patterns. Transportation Research A 39 (10), 835-848.

Tippins, M. and L.K. Stroh (1993) The 4/4 work schedule: impact on employee productivity and work attitudes in a continuous operation industry. Journal of Applied Business Research 9 (3), 136-145.

Van Exel, N.J.A. and P. Rietveld (2009) Could you have made this trip by another mode? An investigation of perceived travel possibilities of car and train travellers on the main travel corridors to the city of Amsterdam, the Netherlands. Transportation Research A 43 (4), 374-385.

Vandenbulcke, G., I. Thomas, B. de Geus, B. Degraeuwe, R. Torfs, R. Meeusen., and L. Int Panis (2009) Mapping bicycle use and the risk of accidents for commuters who cycle to work in Belgium. Transport Policy 16 (2), 77-87.

Vanoutrive, T., L. Van Malderen, B. Jourquin, I. Thomas, A. Verhetsel and F. Witlox (2010) Mobility management measures by employers: overview and exploratory analysis for Belgium. European Journal for Transport and Infrastructures Research 10 (2), 121141.

Vickerman, R.W. (2003) Transport in integrating Europe: sustainable development and cohesion. Investigaciones Regionales 3, 163-174

Walls, M., E. Safirova and Y. Jiang (2006) What drives telecommuting? The relative impact of worker demographics, employer characteristics, and job types. Discussion paper RFF 06-41.

Ward, J.H. (1963) Hierarchical grouping to optimize an objective function. Journal of American Statistical Association 58 (301), 236-244. 


\section{Appendices}

Appendix A: HTWT surveys - Mobility Measures and their frequency

\begin{tabular}{|c|c|c|c|c|}
\hline \multirow{2}{*}{$\begin{array}{l}\text { Mode of } \\
\text { transport }\end{array}$} & \multirow[b]{2}{*}{ Description of the measure } & \multirow{2}{*}{ 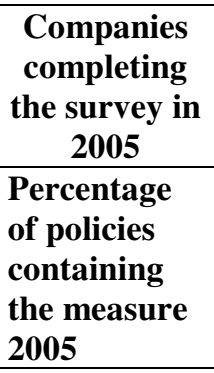 } & \multicolumn{2}{|c|}{$\begin{array}{c}\text { Companies completing the } \\
\text { survey in both } 2005 \text { and } \\
2008\end{array}$} \\
\hline & & & $\begin{array}{l}\text { Percentage } \\
\text { of policies } \\
\text { containing } \\
\text { the measure } \\
2005\end{array}$ & $\begin{array}{l}\text { Percentage } \\
\text { of policies } \\
\text { containing } \\
\text { the measure } \\
2008\end{array}$ \\
\hline \multirow[t]{15}{*}{ Bicycle } & Covered bicycle storage & 34.85 & 37.09 & 48.21 \\
\hline & Secured bicycle storage & 28.74 & 30.13 & 35.27 \\
\hline & Showers & 24.12 & 29.07 & 34.95 \\
\hline & Provision of a changing room & 23.35 & 25.27 & 34.11 \\
\hline & Bicycle repair facilities & 3.06 & 3.27 & 4.39 \\
\hline & Improvement of the infrastructure & 2.90 & 2.73 & 4.05 \\
\hline & Provision of rain clothes & 1.61 & 1.16 & 3.09 \\
\hline & Making bicycles available for work trips & 9.20 & 8.70 & 11.56 \\
\hline & Bicycle maintenance facilities & 1.27 & 1.06 & 1.61 \\
\hline & Making bicycles available for commuting & 0.84 & 0.89 & 3.13 \\
\hline & Bicycles available at the railway station & 0.64 & 0.68 & 1.03 \\
\hline & Cycling measures: other & 7.29 & 8.08 & 6.90 \\
\hline & Diffusion of information about cycling routes & 2.88 & 2.72 & 3.29 \\
\hline & Additional payment for cycle commuting & 42.76 & 42.38 & 46.89 \\
\hline & Additional payment for work trips by bicycle & 7.18 & 6.82 & 9.44 \\
\hline \multirow{6}{*}{$\begin{array}{l}\text { Public } \\
\text { transport }\end{array}$} & Additional payment for using public transport & 23.80 & 24.19 & 25.03 \\
\hline & Organisation of public transport by employers & 4.61 & 5.39 & 6.31 \\
\hline & Coordination with public transport authorities & 5.09 & 5.45 & 6.44 \\
\hline & Diffusion of information about public transport & 9.76 & 10.60 & 12.59 \\
\hline & Encouragement to use public transport for work trips & 6.77 & 6.99 & 9.49 \\
\hline & Other & 8.93 & 8.86 & 8.54 \\
\hline \multirow[t]{6}{*}{ Carpooling } & Organisation of carpooling & 5.23 & 5.79 & 7.88 \\
\hline & Carpooling database & 4.64 & 4.99 & 8.31 \\
\hline & Reserved car parks for carpoolers & 1.89 & 2.18 & 3.05 \\
\hline & Guarantee for the return journey & 1.55 & 1.80 & 2.71 \\
\hline & Diffusion of information about carpooling & 4.25 & 4.75 & 6.81 \\
\hline & Other & 3.77 & 4.09 & 4.15 \\
\hline General & Mobility manager & 3.60 & 3.61 & 9.52 \\
\hline
\end{tabular}


Appendix B: HTWT survey 2005 - Mobility problems and their frequency

\begin{tabular}{|l|l|r|r|}
\hline & & $\begin{array}{l}\text { Percentage of } \\
\text { all companies } \\
\text { mentioning this, } \\
\text { Transportation mode }\end{array}$ & $\begin{array}{l}\text { Percentage of } \\
\text { companies that } \\
\text { completed both } \\
\text { questionnaires } \\
\text { mentioning this, } \\
\text { 2005 }\end{array}$ \\
\hline Car and motorbike & Description of the problem & 14.42 & 14.20 \\
& Dangerous traffic & 25.60 & 23.04 \\
& Inadequate number of parking places for cars & 4.56 & 4.65 \\
& High cost of car parks for employer & 26.12 & 26.19 \\
& Traffic jams & 5.94 & 5.93 \\
\hline Bicycle & Other & 37.33 & 38.11 \\
& Dangerous traffic & 5.99 & 5.81 \\
& Social insecurity & 1.47 & 1.18 \\
& Image of bicycle inadequate with the company & 10.41 & 9.48 \\
& No secured bicycle storage & 18.67 & 17.35 \\
& No showers & 7.93 & 8.06 \\
\hline \multirow{2}{*}{ Public } & Other & 25.72 & 27.27 \\
transport & Inadequate or no public transport & 27.91 & 29.11 \\
& Inappropriate timetables on public transport & 18.84 & 19.66 \\
& Long travelling times on public transport & 7.75 & 7.73 \\
& Poor quality, comfort and security & 15.24 & 15.91 \\
& Distance to the bus stop/station & 5.75 & 5.69 \\
& Feeling of insecurity in the surrounding area & 5.75 & 6.05 \\
\hline \multirow{2}{*}{ All } & Other & 7.61 & 7.85 \\
& Road insecurity & 5.80 & 6.01 \\
\hline
\end{tabular}


Appendix C: Analysis of mobility policies promoting the use of bicycles: logistic regression of the HTWT survey 2005

\begin{tabular}{|c|c|c|c|c|}
\hline \multicolumn{5}{|c|}{ Model fit statistics } \\
\hline Test & $\begin{array}{c}\text { Chi- } \\
\text { Square } \\
\end{array}$ & DF & P > Chi Square & \\
\hline Likelihood ratio & 416.36 & 15 & $<.0001$ & \\
\hline Score & 398.48 & 15 & $<.0001$ & \\
\hline Wald & 336.67 & 15 & $<.0001$ & \\
\hline \multicolumn{5}{|c|}{ Association of predicted probabilities and observed responses } \\
\hline $\begin{array}{l}\text { Percent concordant } 72.1 \\
\text { Percent discordant } 27.4 \\
\text { Percent tied } 0.5\end{array}$ & \multicolumn{3}{|c|}{$\begin{array}{l}\text { Sommers' } \\
\text { D } 0.447 \\
\text { Gamma } \\
0.449 \\
\text { C } \\
0.724 \\
\end{array}$} & \multirow[b]{2}{*}{$\begin{array}{l}\text { P }>\text { Chi } \\
\text { Square }\end{array}$} \\
\hline Variables & Type & $\begin{array}{c}\text { Paramet } \\
\text { er } \\
\end{array}$ & $\begin{array}{l}\text { Standard } \\
\text { deviation }\end{array}$ & \\
\hline Intercept & $\begin{array}{c}- \\
\text { Continuou }\end{array}$ & -2.1224 & 0.1717 & $<.0001$ \\
\hline Number of workers & $\mathrm{s}$ & -0.0017 & 0.0003 & $<.0001$ \\
\hline Covered bicycle storage & Binary & 0.0039 & 0.0095 & $<.0001$ \\
\hline Showers & Binary & -0.0030 & 0.0009 & 0.0017 \\
\hline Bicycle repair facilities & Binary & -0.0050 & 0.0022 & 0.0227 \\
\hline Making bicycles available for work trips & Binary & 0.0069 & 0.0011 & $<.0001$ \\
\hline Diffusion of information about cycling routes & Binary & 0.0041 & 0.002 & 0.0377 \\
\hline Additional payment for cycle commuting & $\begin{array}{l}\text { Binary } \\
\text { Continuou }\end{array}$ & 0.0031 & 0.001 & 0.0023 \\
\hline Number of bicycle racks & $\mathrm{s}$ & 0.0058 & 0.0008 & $<.0001$ \\
\hline Built-up area & Binary & -1.1661 & 0.1312 & $<.0001$ \\
\hline Suburbs & Binary & -0.3837 & 0.1415 & 0.0067 \\
\hline City centre & Binary & -0.9460 & 0.0939 & $<.0001$ \\
\hline Inadequate number of parking places for cars & Binary & 0.0027 & 0.0009 & 0.0041 \\
\hline Dangerous cycling conditions & Binary & -0.0020 & 0.0009 & 0.0185 \\
\hline Feeling of insecurity in the surrounding area & Binary & -0.0052 & 0.0023 & 0.0224 \\
\hline Close to the bus stop/station & Binary & 0.6786 & 0.137 & $<.0001$ \\
\hline
\end{tabular}

\begin{tabular}{|c|c|c|c|c|}
\hline \multicolumn{5}{|c|}{ Model fit statistics } \\
\hline \multicolumn{2}{|l|}{ Test } & $\begin{array}{c}\text { Chi- } \\
\text { Square }\end{array}$ & DF & $\begin{array}{l}\text { P > Chi } \\
\text { Square }\end{array}$ \\
\hline \multirow{3}{*}{\multicolumn{2}{|c|}{$\begin{array}{l}\text { Likelihood ratio } \\
\text { Score } \\
\text { Wald }\end{array}$}} & 416.36 & 15 & $<.0001$ \\
\hline & & 398.48 & 15 & $<.0001$ \\
\hline & & 336.67 & 15 & $<.0001$ \\
\hline \multicolumn{5}{|c|}{$\begin{array}{l}\text { Association of predicted probabilities and observed responses } \\
\end{array}$} \\
\hline \multirow{3}{*}{\multicolumn{2}{|c|}{$\begin{array}{l}\text { Percent concordant } 72.1 \\
\text { Percent discordant } 27.4 \\
\text { Percent tied } 0.5\end{array}$}} & \multirow{3}{*}{\multicolumn{3}{|c|}{$\begin{array}{lr}\text { Sommers' D } & 0.447 \\
\text { Gamma } & \mathbf{0 . 4 4 9} \\
\text { C } & \mathbf{0 . 7 2 4} \\
\end{array}$}} \\
\hline & & & & \\
\hline & & & & \\
\hline Variables & Type & Parameter & $\begin{array}{c}\text { Standard } \\
\text { deviation }\end{array}$ & $\begin{array}{l}\text { P > Chi } \\
\text { Square }\end{array}$ \\
\hline Intercept & - & -2.1224 & 0.1717 & $<.0001$ \\
\hline Number of workers & Continuous & -0.0017 & 0.0003 & $<.0001$ \\
\hline Covered bicycle storage & Binary & 0.0039 & 0.0095 & $<.0001$ \\
\hline Showers & Binary & -0.0030 & 0.0009 & 0.0017 \\
\hline
\end{tabular}




\begin{tabular}{|l|l|c|c|c|} 
Bicycle repair facilities & Binary & -0.0050 & 0.0022 & 0.0227 \\
Making bicycles available for work trips & Binary & 0.0069 & 0.0011 & $<.0001$ \\
Diffusion of information about cycling routes & Binary & 0.0041 & 0.002 & 0.0377 \\
Additional payment for cycle commuting & Binary & 0.0031 & 0.001 & 0.0023 \\
Number of bicycle racks & Continuous & 0.0058 & 0.0008 & $<.0001$ \\
Built-up area & Binary & -1.1661 & 0.1312 & $<.0001$ \\
Suburbs & Binary & -0.3837 & 0.1415 & 0.0067 \\
City centre & Binary & -0.9460 & 0.0939 & $<.0001$ \\
Inadequate number of parking places for cars & Binary & 0.0027 & 0.0009 & 0.0041 \\
Dangerous cycling conditions & Binary & -0.0020 & 0.0009 & 0.0185 \\
Feeling of insecurity in the surrounding area & Binary & -0.0052 & 0.0023 & 0.0224 \\
Close to the bus stop/station & Binary & 0.6786 & 0.137 & $<.0001$ \\
\hline
\end{tabular}


Appendix D: Analysis of mobility policies promoting the use of public transport: logistic regression of the HTWT survey 2005

\begin{tabular}{|c|c|c|c|c|}
\hline \multicolumn{5}{|c|}{ Model fit statistics } \\
\hline Test & & $\begin{array}{c}\text { Chi- } \\
\text { Square } \\
\end{array}$ & DF & $\begin{array}{l}\text { P > Chi } \\
\text { Square }\end{array}$ \\
\hline Likelihood ratio & & 468.79 & 15 & $<.0001$ \\
\hline Score & & 348.01 & 15 & $<.0001$ \\
\hline Wald & & 220.55 & 15 & $<.0001$ \\
\hline \multicolumn{5}{|c|}{ Association of predicted probabilities and observed responses } \\
\hline \multirow{3}{*}{\multicolumn{2}{|c|}{$\begin{array}{l}\text { Percent concordant } 81.4 \\
\text { Percent discordant } 18.2 \\
\text { Percent tied } 0.4\end{array}$}} & \multirow{3}{*}{\multicolumn{3}{|c|}{$\begin{array}{ll}\text { Sommers' D } & 0.632 \\
\text { Gamma } & 0.635 \\
\text { C } & 0.816\end{array}$}} \\
\hline & & & & \\
\hline & & & & \\
\hline Variables & Type & Parameter & $\begin{array}{l}\text { Standard } \\
\text { deviation }\end{array}$ & $\begin{array}{l}\text { P > Chi } \\
\text { Square }\end{array}$ \\
\hline Intercept & - & -7.5935 & 0.8032 & $<.0001$ \\
\hline Number of workers & Continuous & 0.0006 & 0.0001 & 0.0003 \\
\hline Additional payment for using public transport & Binary & 0.0467 & 0.0073 & $<.0001$ \\
\hline Coordination with public transport authorities & Binary & -0.0086 & 0.0023 & 0.0002 \\
\hline Diffusion of information about public transport & Binary & 0.0037 & 0.0019 & 0.0509 \\
\hline $\begin{array}{l}\text { Encouragement to use public transport for work } \\
\text { trips }\end{array}$ & Binary & 0.0034 & 0.0018 & 0.0569 \\
\hline Other & Binary & 0.0053 & 0.0022 & 0.0147 \\
\hline Built-up area & Binary & 1.6346 & 0.2244 & $<.0001$ \\
\hline Suburbs & Binary & -1.3061 & 0.5446 & 0.0165 \\
\hline Industrial zone & Binary & -1.1087 & 0.4105 & 0.0069 \\
\hline City centre & Binary & 1.1691 & 0.2096 & $<.0001$ \\
\hline Dangerous cycling conditions & Binary & 0.0042 & 0.0013 & 0.0008 \\
\hline Inappropriate timetables for public transport & Binary & -0.0049 & 0.0016 & 0.003 \\
\hline Long travelling times on public transport & Binary & -0.0031 & 0.0016 & 0.0485 \\
\hline Feeling of insecurity in the surrounding area & Binary & 0.0053 & 0.0023 & 0.0225 \\
\hline Close to the bus stop/station & Binary & 0.7738 & 0.2721 & 0.0045 \\
\hline
\end{tabular}


Appendix E: Differences between the mean proportion of car users in the $\mathbf{4}$ groups of companies - HTWT survey 2008

\begin{tabular}{|l|l|l|l|l|}
\hline \multicolumn{5}{|c|}{ Mobility policies } \\
\hline & Ongoing & New & Stopped & Never \\
\hline Ongoing & - & & & \\
New & $4.50 * * *$ & - & & \\
Stopped & $7.35 * * *$ & 2.85 & - & \\
Never & $4.62 * * *$ & 0.18 & $-2.73 * * *$ & - \\
\hline \multicolumn{5}{|c|}{$* * *$ Significant difference at the 0.05 level } \\
\hline
\end{tabular}

Appendix F: Differences between the mean proportion of cyclists in the 4 groups of companies - HTWT survey 2008

\begin{tabular}{|l|l|l|l|l|}
\hline \multicolumn{5}{|c|}{ Mobility policies } \\
\hline & Ongoing & New & Stopped & Never \\
\hline Ongoing & - & & & \\
New & $-2.12 * * *$ & - & & \\
Stopped & $-3.80 * * *$ & $-1.64 * * *$ & - & \\
Never & $3.50 * * *$ & -1.37 & 0.30 & - \\
\hline \multicolumn{6}{|c|}{ Significant difference at the 0.05 level } \\
\hline
\end{tabular}

Appendix G: Differences between the mean proportion of public transport users in the 4 groups of companies - HTWT survey 2008

\begin{tabular}{|l|l|l|l|l|}
\hline \multicolumn{5}{|c|}{ Mobility policies } \\
\hline & Ongoing & New & Stopped & Never \\
\hline Ongoing & - & & & \\
New & 0.23 & - & & \\
Stopped & -0.31 & -0.54 & - & \\
Never & -0.91 & -1.15 & -0.61 & - \\
\hline \multicolumn{5}{|c|}{ *** Significant difference at the 0.05 level } \\
\hline
\end{tabular}

Appendix H: Differences between the mean proportion of carpoolers in the 4 groups of companies - HTWT survey 2008

\begin{tabular}{|l|l|l|l|l|}
\hline \multicolumn{5}{|c|}{ Mobility policies } \\
\hline & Ongoing & New & Stopped & Never \\
\hline Ongoing & - & & & \\
New & $-2.35 * * *$ & - & & \\
Stopped & $-3.17 * * *$ & -0.82 & - & \\
Never & -0.60 & 1.74 & 2.57 & - \\
\hline \multicolumn{5}{|c|}{ * Significant difference at the 0.05 level } \\
\hline
\end{tabular}


Appendix I: Changes in the mean proportion of cyclists between 2005 and 2008, related to some mobility measures

\begin{tabular}{|l|l|l|}
\hline \multicolumn{1}{|c|}{ Mobility measure } & \multicolumn{1}{c|}{ Stopped } & \multicolumn{1}{c|}{ Other } \\
\hline Provision of rain clothes & -3.00 & 0.69 \\
Bicycle maintenance & -0.98 & 0.68 \\
Showers & 0.08 & 0.75 \\
\hline
\end{tabular}

Appendix $\mathbf{J}$ - The mean proportions of commuters in each company using particular means of transport in $\mathbf{2 0 0 8}$, related to some mobility measures

\begin{tabular}{|l|l|l|l|}
\hline & \multicolumn{1}{|c|}{ Mobility measure } & \multicolumn{1}{c|}{ Ongoing } & \multicolumn{1}{c|}{ Other } \\
\hline \multirow{5}{*}{ Bicycle } & Additional payment for cycle commuting & 11.57 & 7.75 \\
& Additional payment for work trips by bicycle & 15.04 & 8.78 \\
& Covered bicycle storage & 12.03 & 8.00 \\
& Making bicycles available for work trips & 19.00 & 8.57 \\
Public & Additional payment for using public transport & 21.23 & 12.15 \\
transport & Diffusion of information about public transport & 21.59 & 13.02 \\
& Encouragement to use public transport for work trips & 31.09 & 13.00 \\
& Coordination with public transport authorities & 19.43 & 13.20 \\
\hline Carpool & Organisation of carpooling & 5.24 & 2.83 \\
\hline \multicolumn{2}{|l|}{} \\
\hline
\end{tabular}

